\title{
Intersemiótica e semiótica da figuratividade visual em Morte e vida Severina, de João Cabral de Melo Neto
}

Valdenildo dos Santos*

\section{Resumo}

Com base nos conceitos de intersemiótica, este artigo trata da passagem do poema aos quadrinhos, dos quadrinhos à animação, a quinese, velejando pelos conceitos da obra de arte para Walter Benjamin, da tradução para Roman Jakobson, do signo estético, da transposição de uma a outra linguagem em Morte e vida Severina, de João Cabral de Melo Neto, com base em Julio Plaza e sua obra Tradução intersemiótica. Em um segundo momento, o texto apresenta considerações sobre diálogos entre Peirce e Greimas na esteira de Nícia Ribas D’Ávila, culminando com uma análise sob efeitos de sentido do desenho animado homônimo, uma versão audiovisual do poeta pernambucano, adaptada para os quadrinhos pelo cartunista Miguel Falcão, por meio da teoria da figuratividade visual de inspiração greimasiana, momento em que se identifica a categoria semântica da estacidade versus dinamicidade como par principal entre a linguagem empregada no poema e aquela do desenho animado.

Palavras-chave: Intersemiótica. Signo estético. Semiótica da figuratividade.

\section{Introdução}

Acho que todos os meios deveriam ser usados pelos poetas, dentro desse conceito de que poesia é linguagem afetiva: o rádio, a publicidade, a lírica da música popular, o anedotário da cidade - tudo (MELO NETO, 2008 p. XXVIII).

Era desejo de João Cabral de Melo Neto a utilização de objetos modais dos mais diversos no espectro da poesia enquanto linguagem afetiva, afinal, é no seio do povo que encontramos a identificação das emoções, das coisas do coração em relação às emoções depreendidas no interior do poema.

\footnotetext{
Professor Adjunto IV da Universidade Federal do Mato Grosso do Sul, Campus Três Lagoas. Pós-doutorando na PURDUE University, West Lafayette, Indiana, Estados Unidos, no Department of Languages and Cultures, e leader do Grupo de Pesquisa em Ensino e Aprendizado de Línguas e Leituras Semióticas. E-mail: vdossant@purdue.edu / lavsotnas@hotmail.com / valdenildo.santos@ufms.br
}

Data de submissão: 29/11/2016 - Data de aceite: 22/03/2017 http://dx.doi.org/10.5335/rdes.v13i1.6577 
Desse ponto de vista, o cartunista Miguel Falcão soube como atender esse anseio do poeta pernambucano, ao produzir o desenho animado Morte e vida Severina, homônimo da obra de Melo Neto, uma versão audiovisual adaptada para os quadrinhos postos em movimento. Este artigo, portanto, observa os signos e suas transmutações na transposição das mensagens que carregam de uma forma a outra de expressão, mantendo as suas características iniciais nas pegadas de Júlio Plaza e sua obra Tradução intersemiótica (2008).

Afirma-se que a obra de Falcão reflete essa transposição de signos linguísticos, observados através do intralinguismo, do interlinguismo (Jakobson) e da intersemiótica propriamente dita em signos não verbais. É essa transmutação, produto da criação de Falcão, ou seja, a criação do desenho animado que procura traduzir de maneira dinâmica os movimentos, os sentidos encontrados na poesia de Melo Neto.

A teoria da figuratividade visual, também conhecida como teoria daviliana, ao final, mostra que é possível partir dos signos linguísticos em Peirce e se chegar aos aspectos discursivos que recobrem o texto em Greimas, tornando clara a isotopia viso-temática da retilinidade (tracemas retilíneos englobantes), para a retratação do caráter verbo-imagético (sincrético) presente na produção de Falcão, em uma dança perfeita das linguagens, desde a estaticidade do poema até a dinamicidade do desenho animado.

\section{Da tradução à tradução intersemiótica: o signo estético}

Walter Benjamin, em seu ensaio "A obra de arte na era de sua reprodutibilidade técnica" (1961), tratou do caminho percorrido pela arte principalmente depois do advento da fotografia e, posteriormente, do cinema. Aspectos como a tradução e a adaptação tornaram-se comuns a partir do momento em que a arte deixou de ser alocada em um só lugar, o que limitava consideravelmente $o$ seu alcance, e passou a ser amplamente reproduzida e apreciada por pessoas de várias culturas e línguas distintas.

Em seu artigo "Aspectos linguísticos da tradução ", Roman Jakobson(1995) distinguiu três processos possíveis que acontecem separadamente (ou não): um realizado dentro dos signos verbais de uma mesma língua (intralingual), outro realizado entre signos verbais de línguas distintas (interlingual) e outro chamado de tradução intersemiótica ou transmutação, que consiste em interpretação de signos verbais por signos não verbais.

Os signos não verbais também são estudados pela semiótica da Escola de Paris, quando seus seguidores se debruçam sobre a linguagem não verbal ou sincrética e trazem em si uma manipulação aos observadores pela sedução, pelo fato de chamar a atenção do observador, como alguém que para diante de um quadro e começa a observá-lo. O simples parar já é uma indicação de que foi seduzido a 
olhar para o quadro. Ao tentar entendê-lo, decodificar a mensagem ali posta ou mesmo interpretá-lo de maneira mais objetiva no viés de uma teoria qualquer, temos uma segunda manipulação que se aflora, a qual chamamos de provocação. É como se o quadro lhe dissesse: "Duvido que você consiga me decifrar!".

É esse efeito estésico que seduz, via signo estético (predominante nas artes), e que, para Júlio Plaza, possui particularidades que devem ser levadas em conta nos processos de tradução, posto que ele "não quer comunicar algo que está fora dele, nem 'distrair-se de si' pela remessa a um outro signo, mas colocar-se ele próprio como objeto" (2003, p. 25). São essas características peculiares ao signo estético que influenciam diretamente no modo como o receptor da obra irá reagir diante de determinado objeto, de certo quadro/signo. Conforme Plaza, esse objeto está "apto a produzir como interpretante simplesmente qualidades de sentimentos inanalisáveis, inexplicáveis e inintelectuais" (2003, p. 25). Esses sentimentos, no entanto, podem ser interpretados à luz dos efeitos de sentidos estésicos, quinésicos, patêmicos e até mesmo sinestésicos, se os investigarmos na reação de alguém que está em silêncio em um ambiente e que começa a reagir mediante o som de uma música qualquer que se começa a tocar ao piano, por exemplo.

Há alguns anos, questionamentos sobre a possível intraduzibilidade do signo estético vêm sendo levantados por teóricos da área. Para alguns, as dificuldades relacionadas à tradução seriam amenizadas se o tradutor encarasse seu trabalho como uma forma de transcriação, não apenas de mera substituição do suporte e equivalência de significados. Esse modo de traduzir exige bem mais do que qualquer automatismo, é preciso que coexistam, nesse processo, análise, crítica e conhecimento das especificidades inerentes a cada obra.

Sobre isso, Plaza afirma que:

[...] a tradução como forma estética, não é uma simples transferência de unidade para unidade, do complexo de um sistema sígnico para outro, pois toda unidade constrói o seu sentido e significação numa unidade maior que a incluem. Assim, não se traduz termo a termo, traduz-se sincronicamente os aspectos envolvidos (2003, p. 72).

Por isso, ele distingue três tipos de tradução intersemiótica: uma que se pauta no princípio de similaridade (icônica), bebendo na fonte de Charles Sanders Peirce, outra que se pauta no contato entre original e tradução, no qual o objeto imediato muda e carrega parte ou toda a informação do original (indicial), e a tradução ocorrida por uma contiguidade instituída (simbólica), quando há muito mais importância nos aspectos culturais e intelectuais que o circundam quando esse signo é traduzido. Nota-se que Plaza baseia-se na semiótica americana de Charles Sanders Peirce em relação à sua tricotomia: índice, ícone e símbolo, bem como nas idades do signo. 


\section{Peirce, Greimas e a teoria da figuratividade visual}

No artigo "Diálogos entre C. S. Peirce e A.-J. Greimas”, Nícia Ribas D’Ávila explica os motivos pelos quais utiliza as teorias dos dois estudiosos,

Ultrapassando os vastos domínios do signo (em Peirce) sem jamais esgotá-los, buscamos uma complementaridade na ciência da significação (em Greimas), transfrástica / enunciva e enunciativa/, lembrando porém que ambas as teorias se completam e sempre contribuirão à elaboração de estudos semióticos aprofundados àqueles cujo egocentrismo é bem menos importante do que as necessidades evolutivas da ciência. A valorização da competência intelectual desses 2 gênios que dialogam de uma certa forma nesse trabalho, será nosso enfoque na esperança de que se possa fazer ciência com dignidade e respeito (2001, p. 65).

Em Semiótica sincrética aplicada: novas tendências, obra organizada pela semioticista, esses mestres são chamados de "gênios que não se antagonizam, mas que se acrescentam" (2007, p. 48).

O diálogo entre Peirce e Greimas segundo D’Ávila reside no fato de que ambos foram importantes em suas pesquisas sobre os blocos sonoros, o ritmo. D'Ávila dedicou-se ao estudo da semiótica americana por cinco anos, antes de enveredar-se pela teoria da significação de Greimas e defender tese de doutoramento sob sua orientação na Universidade de Sorbonne, França, em 1987, em semiótica musical, analisando a batucada nas Escolas de Samba do Rio de Janeiro, tendo na banca de defesa o próprio Greimas ao lado de Jean Claude Coquet. $^{2}$

A semioticista da figuralidade ou figuratividade visual constatou que a recepção tímica imediata e irrefletida da captação da "recepção tímica eufórica / disfórica de blocos sonoros (aspecto ativo) ou de uma obra de arte (figurativa ou não)", chamada de efeito de sentido na semiótica do mestre lituano, pode ter como sinônimo "a categoria de primeiridade", em Charles Sanders Peirce: "Dela colhíamos a sensação do observado em si, sem nenhuma referência a qualquer outra coisa. Inicialmente um ícone puro, um impacto, um flash sobre a percepção" (2001, p. 66, grifo da autora). Foi com as pesquisas da semiótica de Peirce que descobriu, mais tarde, "vários níveis de iconicidade em função do percepto, tais como: qualidade globalizada/individualizada/ou regra coletiva" (2001, p. 71).

D’Ávila cita Greimas, que informa que "essas instâncias iniciais, cujo sentido não pode ainda ser articulado, são consideradas como efeito de sentido, 'única realidade apreensível, mas que não pode ser apreendida de maneira imediata' e estão situadas 'na instância da recepção' e que correspondem 'à semiose, ato situado no nível da enunciação e à sua manifestação que é o enunciado-discurso' e que correspondem 'à ilusão referencial' (Barthes)” (2001, p. 71-72).

Charles Sanders Peirce retoma o conceito de ícone como um signo referente ao objeto com propriedade denotativa somente em virtude de sua própria 
característica na existência ou não do objeto, o que implica dizer que:

Qualquer coisa, seja uma qualidade, um existente ou individual ou uma lei, é ícone de qualquer coisa, na medida em que for semelhante a essa coisa e utilizado como um seu signo (1903, p. 247).

Peirce fala ainda do ícone puro, ao qual vai chamar de possibilidade lógica, não singular tal qual uma ideia, mas como representante fiel do objeto e, neste caso, o ícone é o próprio objeto. Por ser uma possibilidade lógica e não algo existente, no dizer de Peirce, o ícone puro assim se manifesta porque o signo em sua possibilidade de relação com o objeto de natureza existencial passa a ser encarado como índice e não como um ícone.

Já o símbolo, nessa categorização da primeiridade, secundidade e terceiridade, extrapola essa categoria e a simples relação de semelhança, caso específico do ícone que representa o objeto por conta da comunhão de qualidades produtora da semelhança entre o ícone e' o objeto. Se a existência pressupõe a secundidade, $o$ ícone puro não vai existir, porque existe uma isotopia fusional entre ele, o ícone puro e o objeto, pelo fato de o primeiro não fazer distinção do segundo.

É com base na não existência de um ícone puro que Peirce apresenta os hipoícones como uma possibilidade, aquela que nos fala da primeiridade e, nesse caso, não é ícone, mas índice. O signo, por sua vez, pode ser icônico ao representar por meio da similaridade. Assim, o hipoícone será um representâmen, na formulação piramidal peirceana, dado o seu potencial de representar o objeto via similaridade.

Ao formular as três categorias lógicas universais da primeiridade, secundidade e terceiridade, Peirce dá as dicas do modo de ser do hipoícone, relacionando a primeiridade à qualidade do signo (índice), a secundidade à sua relação (ícone) e a terceiridade a uma lei universal (símbolo), sendo que esta última depende das duas primeiras, por ser por elas constituída, e a segunda depende também da primeira.

Os hipoícones participam, assim, da primeiridade quando essa se constitui pelas qualidades simples ou primeiras, como é o caso das imagens. Eles participam também da secundidade quando representam relações diádicas ou não das partes de algo por relações análogas em suas partes como os diagramas. Eles participam, finalmente, da terceiridade quando representam a própria representatividade de um representâmen via paralelismo com alguma outra coisa, como as metáforas.

Tanto as imagens quanto os diagramas e as metáforas são sinsignos icônicos, porque, no caso das primeiras, elas mantêm relação de similaridade com o seu objeto pelos aspectos qualitativos, dinâmicos e imediatos, uma vez que os objetos que as constituem são de natureza material existente e seus atributos mais importantes são a reflexão, a tensividade superficial, o formato, tamanho relativo, seu desenho, que representa o perfil de uma pessoa ou objeto, de acordo com os contornos que a sua sombra proje- 
ta, e finalmente o seu peso. Os segundos apresentam um padrão de relação pela similaridade com o seu objeto, fazendo com que haja dinamicidade em seu objeto formador de um padrão regular de relações, cujo objeto imediato é um existente. As terceiras apresentam similaridade com seu objeto, baseada em aspectos de lei. Logo, o objeto do hipoícone tem esse caráter pertencente à terceiridade ou a generalização, em uma abrangência maior, simbólica.

Retomados esses conceitos peirceanos pela referencialização do texto daviliano, a fim de entendermos melhor essa analogia, voltemos à proposta aqui engendrada de uma teoria da figuralidade, que procura agora mostrar o nível profundo na comunicação visual e o semissimbolismo de inspiração flocheana, porque D’Ávila cita Jean Marie Floch, contemporâneo de Greimas, que teria contribuído com a semiótica visual, definindo o semissimbolismo como

[..] a manifestação sincrética (verbo-visual), na qual as substâncias da expressão tenham um caráter verbal e visual, para exprimir uma única categoria do conteúdo (2007, p. 42).

Afirma D'Ávila que, "No sincretismo verbo-visual, o visual pode interagir no contexto, alterando o conteúdo do verbal" (2007, p. 42), e sugere que há "potencialidades simbólicas" tanto na linguagem verbal quanto na linguagem não verbal ou sincrética e postula para a sua "Teoria da Figuratividade" "a construção de uma metalinguagem apropriada" (2007, p. 42).
D’Ávila cria neologismos para falar do "signo visual", que, segundo ele, é um "formante" que pertence ao plano da expressão, cujo "formema" pertence ao plano do conteúdo e que é

[...] apreendido pela consciência fundada num objeto posto ou por ela pressuposto, que representa e encerra a própria significação, ou em ideias gerais e específicas que desse algo emanem (2007, p. 43).

O signo visual é, dessa forma, uma constituição da semiose existente entre ambos os planos quando estes se manifestam no interior do texto.

Ela justifica sua posição ao afirmar que é pela linguagem verbal que se reconstitui o que a obra diz, do jeito que diz o que diz, naquela mesma perspectiva da imanência do texto defendida por Greimas em sua teoria e reproduzida por Fiorin, Barros e tantos outros semioticistas. Afinal, quem nunca, no ambiente dessa semiótica, ouviu a repetida frase: "o que o texto diz, do jeito que diz o que diz", ou seja, o percurso gerativo do sentido? É justamente esta a proposta de D’Ávila, criar uma metalinguagem que venha dar conta do "como" do sentido, "o modo por meio do qual ela transmite a sua mensagem, fazendo-se entender" (2007, p. 47), o que já existe no tocante à linguagem verbal, deixada pelo semioticista lituano. É assim que ela percorre sua busca incansável da

natureza dos conteúdos visuais envolvidos nesse tipo de manifestação, principalmente aquela que é desprovida de histórias a narrar, no caso, a obra abstrata (2007, p. 47). 
O quadrado semiótico que mostra a passagem do figural ao figurativo serve de ilustração para melhor compreensão de sua proposta (Figura 1).

Figura 1 - Quadrado semiótico da figuratividade visual

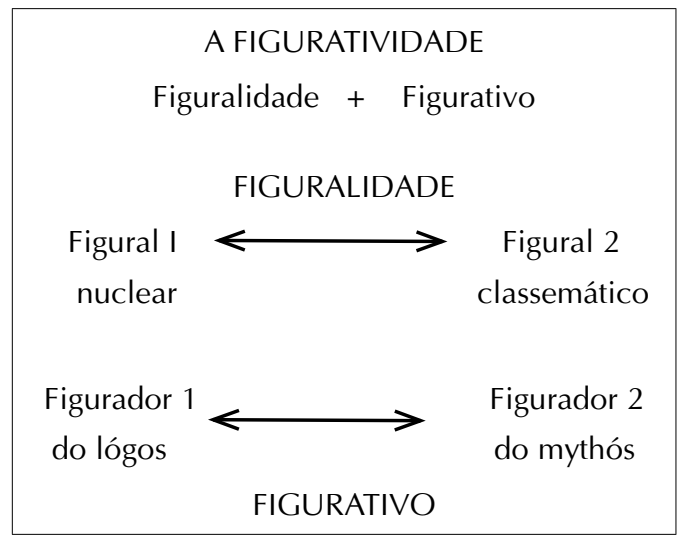

Fonte: D’Ávila (2007, p. 29).

D’Ávila explica o quadrado semiótico da figuratividade visual por meio dos figurais 1 e 2, os quais vão compor o eixo semântico da figuralidade, e dos figuradores 1 e 2, que pertencem ao eixo semântico do figurativo, a soma de ambos traduz-se na figuratividade visual propriamente dita (2007, p. 29). A Figura 2 informa sobre aquilo que pode se representar como símbolo, guiando a "referentes externos".

Figura 2 - Imagem que mostra o figural que leva ao figurativo

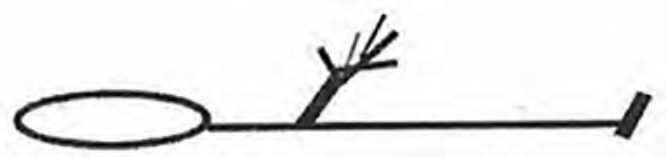

Fonte: D’Ávila (2007, p. 32).
A imagem posta, segundo D'Ávila, serve de ilustração para mostrar sua teorização, porque, "independentemente do que possa representar como símbolo que conduz a referentes externos" -, ela procura desconstruir, do ponto de vista "formal" e sígnico, "todo significante", com vistas a "encontrar a essência na formação do traço, cujas modificações neles efetuadas implicam, consequentemente, a alteração do significado visual" (2007, p. 32).

É essa busca da essência das coisas, dos fenômenos, do "ser" do sujeito, cujo seu não encontro é a frustração dos analistas, dos artistas, como Pablo Picasso já nos indicava em seu touro linha, que D’Ávila procura resolver, ao propor sua teoria e explicar os novos termos, como o "formema complexo", em sua definição,

[...] aquele que possibilita a análise do referente interno do texto ou objeto semiótico, permitindo que o mesmo possa ser interpretado pelas somas contextuais extraídos dos seus figurais classemáticos dos tipos "manchas", ou primitivos figurativos, geradores de isotopias rimas plásticas, projeções (2007, p. 34).

D’Ávila explica que: "O excesso de inclinância (extraído do /ft/) evidencia a isotopia da diagonalidade ascendente, direcionada à direita, indicativa de uma intencionalidade de movimento rítmico" (2007, p. 36), e que ao nível do significado, no plano do conteúdo, "[...] o não-verbal sofre alterações em virtude da necessidade de extraírem-se os conteúdos do material plástico presentificado, representado e re-presentado, face à qua- 
lificação e à quantificação da substância da expressão" (2007, p. 40), conforme veremos no quadro geral do percurso gerativo do sentido na manifestação visual com base no mesmo percurso já delineado por Greimas (Figura 3).

Figura 3 - Os traços figurais representativos do figurativo

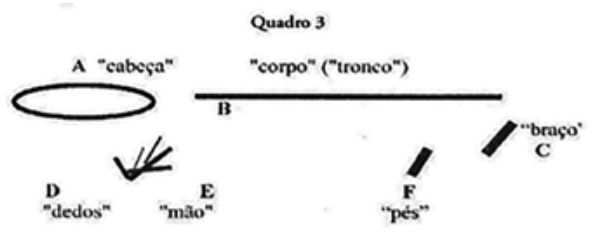

Fonte: D’Ávila (2007, p. 34).

Nessa figura, na semiótica visual, o conteúdo é sinônimo de significado, a substância do conteúdo é variável e a forma do conteúdo é invariável. Assim, a substância do conteúdo apresenta variáveis perceptíveis e se manifesta de maneira triádica, que expõe:

a) a substância do conteúdo em que a presentificação simbólica denotativa, como o figural 2, existente nas artes abstratas e suas variantes; a representação semissimbólica denotativo-conotativa, que apresenta o figurador 1, do logos, o que a imagem representa, sua história retratada com fidelidade ao figurativo que tem implicação com o semantismo verbal e a re-representação, que tem um caráter conotativo, cujo figurador 2 se manifesta, desta vez, do "mythós", bebendo na fonte de Jean Claude
Coquet, em que a representação do objeto apresenta traços subjetivos de seu observador analista que não consegue, como dizia Greimas, isentar-se de sua timia, aqueles efeitos psicofisiológicos, ao que D’Ávila vai chamar de "repertório e criatividade";

b) a forma do conteúdo, na coluna do meio de seu quadro, em que podemos verificar, no nível superficial, o figural e o figurativo.

Ela explica primeiro aquilo que é concernente ao mundo denotativo, como o ritmo, o aspecto, o ritmo dos espaços analisável pela proxêmica, a disposição de objetos em determinado espaço com o fim de significar, como os termos englobante versus englobado, a simetria, a assimetria e o sincretismo, aquilo que está misturado, os aspectos, como o incoativo, isto é, o início de tudo, o durativo, aquilo que ocorre durante, o terminativo, aquilo que é concernente ao fim da operação, o contínuo, aquilo que permanece, o descontínuo, aquilo que é interrompido, o não descontínuo, em uma relação de contrariedade no quadrado semiótico e da mesma forma o não contínuo.

No interior do espaço e do ponto de vista temporal, o que chamamos de espacio-temporalização, 0 analista pode explorar os planos 1, 2, 3, e assim por diante e dentro dos planos, os espaços $1,2,3$, e assim sucessivamente.

Aponta também como verificar as oposições como contorno e contornado, 
a perspectiva como as superfícies e os volumes, a proporcionalidade como dimensão, posição, orientação, rimas plásticas simples e complexas, que vão determinar os classemas, as posições sintagmáticas e paradigmáticas, os planos isotópicos, as sincopas, que pertencem ao figural, e os formemas parciais e totalizantes aos quais abrevia na forma fp e ft.

Os termos em destaque são do mundo denotativo. Do mundo conotativo, sua implicação verbal, as rimas poéticas e míticas e as funções da sincopa no nível figurativo, o ponto de tensão, o figurema, o ponto de transição e o imagema.

Ainda em relação à forma do conteúdo, agora no nível profundo de análise, nota-se que D'Ávila sintetiza a denotação e as categorias semânticas responsáveis pelas isotopias, os semas que mostram as quantificações e a qualificação da figura, o pontuema, o tracema, o angulema, o colorema, o cromena, o saturema, o texturema, o densirema, o largurema, o poietema, o sincopema, o extensurema, o figurema, o projetema, e assim por diante, todos neologismos criados no nível profundo e oriundos dos níveis anteriores.

A autora sugere que eles sejam dispostos no quadrado semiótico a fim de determinar a forma, abstrata ou sistêmica e paradigmática extraída de isotopias como da retilineidade, que podem aparecer na vertical, horizontal, diagonal, perpendicular, cruzada 1 e 2 , na curva côncava, aquela na qual qualquer seg- mento de reta unindo dois de seus pontos está mais próxima do observador que o trecho da curva entre esses pontos, que pode ser horizontalizada, verticalizada, diagonalizada, perpendicularizada, ascendente, descendente, etc.

A curvilineidade pode ainda se apresentar com as mesmas características, porém de forma convexa, ou seja, aquela na qual qualquer segmento de reta unindo dois de seus pontos está mais afastada do observador que o trecho da curva entre esses pontos.

Ao analista cabe notar, ainda, as projeções paradigmáticas que varam $o$ quadro, a estrutura, extrapolam a forma, a cor, ou os movimentos suprasseguimentais, aqueles que deságuam em mais de um seguimento.

D’Ávila destaca, finalmente, que as conversões em que os termos se transformam em valores investidos nos objetos sintáticos, são necessárias, porque podem converter figuras do mundo e esse é um teste que fundamenta a coerência da teoria s emió tica (2007, p. 41), conforme Greimas e Courtés já diziam (1979, p. 87).

É, portanto, com esse suporte teórico que D’Ávila esboça seu modelo constituído de um percurso delineado e organizado para a análise do não verbal e sincrético, com a criação de neologismos e convenções que procuram ampliar, preencher uma lacuna deixada na teoria semiótica da Escola de Paris quanto ao fornecimento de um arcabouço teórico para a análise do discurso não verbal e sincrético. 
A semioticista mostra-se fiel à proposde Greimas, ao fazer questão de citá-lo em relação aos termos que se transformam em valores investidos nos objetos sintáxicos, podendo ser convertidos em figuras e em ícones do mundo. Havia, portanto, a necessidade de outras pesquisas que pudessem fundamentar e mostrar a coerência da teoria semiótica, um desafio para os "discípulos" de Greimas.

No Quadro 1, apresenta-se um resumo do modelo daviliano, que pode ser posto em prática na análise de imagens e de textos sincréticos, chamado de percurso gerativo do sentido na manifestação visual.

Quadro 1 - Percurso gerativo do sentido para a manifestação visual

\begin{tabular}{|c|c|c|}
\hline \multirow{2}{*}{\multicolumn{3}{|c|}{$\begin{array}{l}\text { PERCURSO GERATIVO DO SENTIDO NA MANIFESTAÇÃO VISUAL } \\
\text { Dra. Nícia R. D'Ávi1a } \\
\text { CONTEÚDO (SIGNIFICADO) NO TEXTO VISUAL } \\
\text { TÂNCIA DO CONTEÚDO (Variável) + FORMA DO CONTEÚDO (Invariável) }\end{array}$}} \\
\hline & & \\
\hline $\begin{array}{l}\text { Substância do CONTEÚDO } \\
\text { Variáveis perceptíveis }\end{array}$ & & \\
\hline $\begin{array}{l}\text { a) presentificação } \\
\text { Simbólica (denotativa) (Fi- } \\
\text { gural 2) } \\
\text { Arte abstrata e variantes } \\
\text { s.es*.. } \\
\text { b) Representaçio } \\
\text { Semissimbólica } \\
\text { (denotativo-conotativg) } \\
\text { Figurador } 1 \text { - "do lógos" } \\
\text { Aquilo que a imagem re- } \\
\text { presenta; a história retratada } \\
\text { com fidelidade ao figurativo } \\
\text { e implicação com o seman- } \\
\text { tismo verbal } \\
\text { c) Re-representação (co- } \\
\text { notativa) } \\
\text { Flgurador } 2 \text { - "do mithós". } \\
\text { A representação do objeto é } \\
\text { acrescida da subjetividade } \\
\text { interpretativa do analista } \\
\text { cujos acréscimos fundam- } \\
\text {-se no seu repertório e na } \\
\text { criatividade. }\end{array}$ & $\begin{array}{l}\text { Denotativo } \\
\text { I) Ritmo -F 2) Aspecto. I) O Ritmo dos espa- } \\
\text { ços (na proxêmica): englobante x englobado; } \\
\text { simétrico, assimétrico e misturado; } \\
\text { 2) Aspectos: incoativo, durativo e terminati- } \\
\text { vo, contínuo, descontínuo/ não-descontínuo/ } \\
\text { não contínuo; na espacio-temporalidade, os } \\
\text { planos: } \\
\text { PI, p2, etc., e espaços: el, e2; em, e2"i etc., } \\
\text { (Contorno x contornado). } \\
\text { perspectiva (superfícies e volumes), propor- } \\
\text { cionalidade. } \\
\text { Dimensão/posição/orientação; rimas plásticas } \\
\text { simples e complexas determinantes da natureza } \\
\text { dos classemas. Projeções sintagmáticas } \\
\text { Planos isotópicos } \\
\text { Função de síncopa (figural) } \\
\text { Formema total (ft) e formema parcial (fp) } \\
\text { Conotativo } \\
\text { Impliação verbal, rimas poética-míticas e } \\
\text { funções de síncopa no figurativo. } \\
\text { Ponto de tensão. Figurema; ponto de } \\
\text { transição imagema: }\end{array}$ & $\begin{array}{l}\text { Denotação - cat } \\
\text { isotopias: semas } \\
\text { qualificação da } \\
\text { 'angulema', 'col } \\
\text { 'cromena', 'satur } \\
\text { 'texturema', 'den } \\
\text { 'largurema', 'poi } \\
\text { 'figurema', 'proj } \\
\text { Quadrados } \\
\text { Semióticos para } \\
\text { sistêmica, parad } \\
\text { retilineidade } \\
\text { (horizontalizada, } \\
\text { dicularizada, cru } \\
\text { côncava: } \\
\text { (horizontalizada } \\
\text { dente, diagonali } \\
\text { Da curvilineidad } \\
\text { (horizontalizada } \\
\text { dente, diagonali } \\
\text { Projeções paradi } \\
\text { da cor ou do mo } \\
\text { Conversões }\end{array}$ \\
\hline \multirow{2}{*}{\multicolumn{3}{|c|}{$\begin{array}{l}\text { Estruturas discursivas - Figural I Nuclear - arcabouço das formas figural e figurativa; Propulsor e condensador das substancias e } \\
\text { formas do conteúdo por rupturas e suprassegmentação. }\end{array}$}} \\
\hline & & \\
\hline $\begin{array}{l}\text { Substância (variável) } \\
\text { Físico-ótico-químico } \\
\text { Não é pressuposição da forma. }\end{array}$ & \multicolumn{2}{|c|}{$\begin{array}{l}\text { Forma (invariável) pressupõe a substância } \\
\text { O sistema visual: rede de traços distintivos relacionais, agregados e ordenados em lingua- } \\
\text { gem ora pictural ora gráfico-artística. }\end{array}$} \\
\hline
\end{tabular}

Fonte: D’Ávila (2007, p. 41). 
Observemos agora o quadrado semiótico englobado no círculo da conversão que nos fala da totalidade e das partes do objeto de análise (Figura 4), que mostra a manifestação sincrética (verbo-visual), na qual as substâncias da expressão apresentam um caráter verbal e visual, para exprimir uma única categoria do conteúdo. Esse sincretismo próprio das artes plásticas, como a linguagem verbo-visual, interage com o contexto, alterando o conteúdo do verbal. D'Ávila valoriza as potencialidades simbólicas existentes em cada linguagem e postula a construção de uma metalinguagem apropriada.

Figura 4 - Círculo englobante da conversão

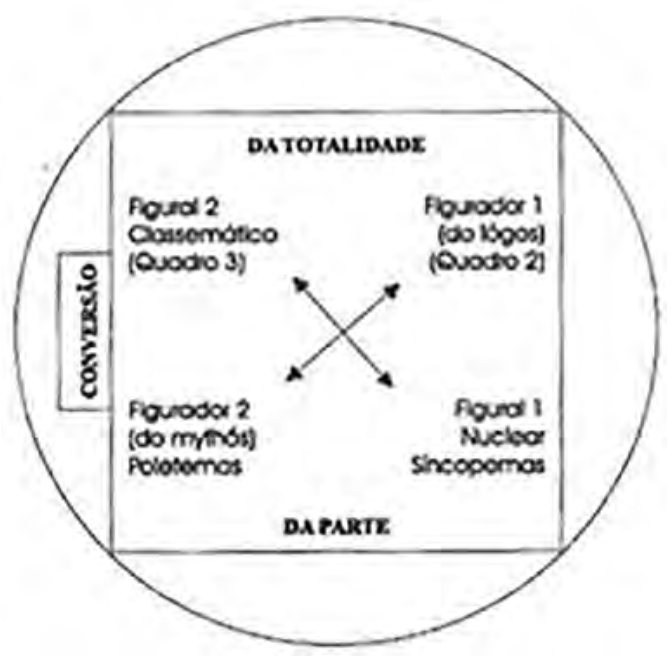

Fonte: D’Ávila (2007, p. 42).

Os estudos de D'Ávila quanto à proposta de uma teoria que busque o que vem antes da figuratividade tiveram início na França, quando assistia às aulas de Greimas sobre umas tais "boîtes noires", "caixas pretas", fazendo-a entender que sua teoria estava em desenvolvimento e que havia ainda alguns espaços a serem preenchidos por pesquisas de seus seguidores. Dessa forma, em um caminho que procura ir além da figuratividade, os propósitos de Nícia Ribas D'Ávila esperam desvendar os segredos da figuralidade, desenvolvendo uma série de artigos ao longo de mais de 20 anos de pesquisa, culminando com Semiótica sincrética aplicada (2007), em que propõe a teoria daviliana aplicada à comunicação visual, às artes plásticas, à música e à literatura, com a exploração do simbolismo e do semissimbolismo.

A proposta daviliana parece ampliar os estudos de Jean Marie Floch, porque procura ir além do aspecto verbal, uma vez que Floch se concentrou na substância do conteúdo e do semissimbolismo ancorados no aspecto verbal, como vemos em suas obras Sémiotique, marketing et communication e Identités visuelles, ambas de 1995, que inspiraram, aqui no Brasil, Análise do texto visual, a construção da imagem (2011) e Semiótica visual, os percursos do olhar (2012), de Antonio Vicente Pietroforte.

Essa preocupação da semiótica em dar conta do sentido no texto literário, no entanto, tem os seus passos iniciais com a publicação de Ensaios de semiótica (1975), obra organizada pelo próprio Greimas, incluindo artigos do semioticista lituano, Michel Arrivé, de Jean- 
-Claude Coquet, Jean-Paul Dumont, Jacques Geninasca, Nicole Gueunier, Jean-Louis Houdebine, Julia Kristeva, François Rastier, Teun A. Van Dijk e Claude Zilberberg. A versão original data de 1972.

Essas reflexões, ora partilhadas, fazem parte do Projeto de Pesquisa "Caixas pretas" e importância da semiótica francesa na análise de discurso verbal, não verbal e sincrético, iniciado em 2013, com término programado para 2018, em que essas caixas pretas podem ser vistas, conforme a definição dicionarística, como "aparelho ou construto com características de apresentação conhecida ou específica cujos constituintes e meios de operação ainda não são conhecidos nem especificados". ${ }^{3}$ É, pelo que compreendemos até o momento, portanto, nessa direção que as pesquisas de D'Ávila trafegam, ao observarmos uma série de artigos da semioticista greimasiana e de alunos que D'Ávila orientou na defesa de mestrados e doutorados ao longo de quase três décadas, alguns dos quais reunidos em dois livros por ela organizados e publicados em 2007 e $2015 .^{4}$

É com base nessa teoria, a qual chamamos de teoria daviliana da figuralidade, porque D'Ávila inova buscando o anterior ao figurativo, criando novos termos e funções, como os pontuemas, os tracemas, os figuremas, etc., que propomos o fechamento deste artigo, ainda que de forma rudimentar, sob efeitos de sentido de sua teoria. Começamos, entretanto, com as oposições já tradicionais de Greimas, inspiradas em Ferdinand de Saussure, cujo sentido apresenta-se pelas diferenças.

Antes, porém, falemos um pouco sobre João Cabral de Melo Neto e de Morte e vida Severina, inspiração para Miguel Falcão e para nós na incansável busca do sentido nesta versão aqui "desenhada" e da origem da quinésica, o movimento do poema, o poema em movimento.

\section{A obra de João Cabral de Melo Neto}

O poema dramático Morte e vida Severina, de João Cabral de Melo Neto, lançado em 1955, foi encomendado por Maria Clara Machado para uma montagem que acabou não acontecendo por suas mãos, só tendo sua primeira edição conhecida em 1965, realizada pelo diretor Roberto Freire e musicada por Chico Buarque.

João Cabral de Melo Neto sempre deixou claro que pretendia que seu auto de natal alcançasse as classes menos privilegiadas da sociedade, por isso, conforme vemos na epígrafe que ilustra a abertura deste trabalho, defende o uso de todos os meios possíveis de comunicação para a divulgação da poesia, mesmo desejo de Greimas ao defender a popularização da ciência (SANTOS, 2014). ${ }^{5}$

Nesse sentido, Cabral trabalhou para que a obra fosse popular não só nos versos utilizados, mas também no assunto tratado, trazendo um personagem principal chamado Severino, que presencia a fome, a sequidão e o sertão permeado 
de morte em quase todo o poema, exceto no trecho final, no qual o personagem se depara com o nascimento de um menino, acontecimento que tem íntima ligação com a história do nascimento de Jesus na cultura cristã.

Desde a sua publicação em 1955, o ao poema dramático vem recebendo montagens teatrais e adaptações diversas. A primeira montagem aconteceu em 1966, no Teatro da Universidade Católica de distinguindo São Paulo, depois surgiram novas adaptações, como o filme de 1977 (com ma "O rio" do autor, de Zelito Viana, e o musical da rede globo, com direção de Walter Avancini, em 19816 (Link II).

Ainda, em 2005, foi lançada uma versão em quadrinhos, criada pelo cartunista pernambucano Miguel Falcão, que manteve o texto integral do poema de João Cabral de Melo Neto. Posteriormente, uma adaptação dessa versão foi realizada pela Fundação Joaquim Nabuco em parceria com a TV Escola dentro de uma série de adaptações chamada "Poemas animados", esta é a adaptação focada nesta análise.

\section{Quinésica, de Birdwhistell à Kristeva: a dança dos movimentos}

Ray L. Birdwhistell fala dos quinemas, a que chama de "unidades distintivas, que são classes de movimentos cujas variantes são denominadas aloquines ou quines", dos quinemorfemas, que designa como classes de quinemorfos e das construções quinemorfas complexas para entrar na análise quinésica propriamente dita (BIRDWHISTEL, 1979, p. 145-146). O estudioso do gesto e dos movimentos explica que "A análise quinésica dedicou-se primeiro estudo do comportamento motor encarado em si mesmo, independentemente de qualquer interação com a linguagem verbal" (1979, p. 145), pelo menos três critérios para estudo das variações: intensidade, amplitude e velocidade.

Não entraremos no mérito da questão, mas apenas introduziremos suas reflexões para procurar fazer saber sobre a relação da quinésica com os movimentos encontrados no poema a partir da transposição da linguagem estática, verbal, para a linguagem dinâmica, não verbal, dos quadrinhos.

Ao transpor o poema da ordem verbal para o não verbal, alcança-se um novo público. Quem não gosta de poesia, do verbal, poderá gostar da poesia nos quadrinhos. O quadrinho tem o poder de se comunicar, por exemplo, com o público adolescente.

Julia Kristeva, em "O Gesto, prática ou comunicação” (1979), retoma o nascimento da quinésica, da quinésica americana e de quinésica e linguística, explicando que os quinesistas indicam Darwin como pioneiro no estudo comunicativo dos movimentos e, em seguida, os trabalhos de Franz Boas, que marcam o nascimento da quinésica americana, destacando que 
[...] foi sobretudo a investigação antropológico-linguística de Edward Sapir, particularmente a sua tese de que a gestualidade corporal é um código que deve ser aprendida com visa ao êxito da comunicação que vem a inspirar as tendências da quinésica atual (KRISTEVA, 1979, p. 80).

Os quadrinhos são entendidos aqui como o poema posto em movimento, a quinese. Santos, em "A música e seus efeitos de sentido como motivadores no ensino de línguas", explica que: "O quinésico fala-nos dos movimentos e posições de cunho psicomuscular conscientes ou inconscientes do sujeito diante de uma cena visual ou da emissão de um som qualquer" (2014, p. 120). Nesse sentido, a personagem reage com movimentos já conhecidos pelo responsável da adaptação e tanto a fala quanto os demais sons são colocados para causar no espectador reações que o façam sentir parte do que sentiria ao ler o poema.

Isso explica porque, em determinados momentos, a fala das personagens ganha ritmo de uma reza, repetida em uníssono no enterro do lavrador, e em outros a fala se amansa, tornando-se reflexiva, principalmente nos momentos em que Severino questiona a situação em que se encontra o meio em que vive. É nos momentos em que a voz ganha tons de lamúria que ele questiona a própria importância da luta pela vida, mesmo emergido em um ambiente no qual o único meio possível de sobrevivência é aquele que trata da morte, nas palavras da "mulher na janela": "Como aqui a morte é tanta/só é possível trabalhar/ nessas profissões que fazem/da morte ofício ou bazar" (MELO NETO, 2010, p. 129).

A animação Morte e vida Severina trouxe o poema homônimo em sua versão integral para as telas, por meio da trilha sonora, o ritmo do poema seguido e do desenho com aspectos rústicos, além da "pedra de nascença entranhada a alma do nordestino", citada em "A educação pela pedra" (2010, p. 271) - outra poesia do autor -, que é a responsável pela eliminação da linha que divide o homem e o espaço no qual nasce, vive e morre.

Severino apresenta-se, assim como ocorre no poema, mas, desta vez, em um processo de simbiose, transforma-se em elementos presentes no espaço árido que observamos. Todas as figuras humanas retratadas possuem características bem genéricas, como se nota no poema no verso "somos muitos severinos/ iguais em tudo na vida" (2010, p. 116).

Para transmitir para a tela a ênfase dada pelo poeta para a presença da morte em um local arrasado pela seca, os olhos das personagens dão lugar a um espaço negro, um "oco". As caveiras são figuras frequentes durante toda a animação. Os urubus, aves muito associadas a cadáveres, são postos como parte do ambiente e são os animais que mais aparecem na adaptação.

Em cenas que retratam o assassinato e o traslado de um homem morto pelo seu pedaço de terra, Severino é colocado no lugar da vítima, tanto no momento do acontecido, como depois, na hora em que 
os "Irmãos das almas" estão carregando o corpo.

A animação segue a mesma ordem estabelecida pelo poema, os acontecimentos se sucedem de forma linear e as mudanças de local explícitas no texto são demonstradas pelas sequências nas quais o personagem caminha sem interação com ninguém, apenas com monólogos e uma trilha formada por música, sons de sinos e de animais.

\section{Delimitação do corpus}

Embora o desenho em pauta seja rico em sua extensão, sua colocação em discurso e análise seria inviável para a modalidade artigo a que nos propomos aqui, portanto o delimitamos a dois recortes que mostram, de forma resumida, a grandeza da temática explorada tanto por João Cabral de Melo Neto quanto por Miguel Falcão.

Começamos, então, a análise por meio da categoria semântica evidenciada no título do poema, aquela que fala da vida em oposição à morte. $\mathrm{O}$ interessante é que o narrador, do ponto de vista do poema, via título, pela ordem, fala primeiro da morte, para depois falar da vida, invertendo o princípio natural de que para existir a morte é preciso primeiro existir a vida. Afinal, por que o poema de Melo Neto não se chama "Vida e morte Severina", mas, ao invés, "Morte e vida Severina"? Que me diz, caro leitor?

$\mathrm{O}$ recorte que segue (Figura 5) mostra com precisão a representação do nordestino comum, do homem comum afetado pela secura da terra, pela pobreza da vida, pela indiferença dos outros homens.

Figura 5 - Morte e vida Severina - desenho animado

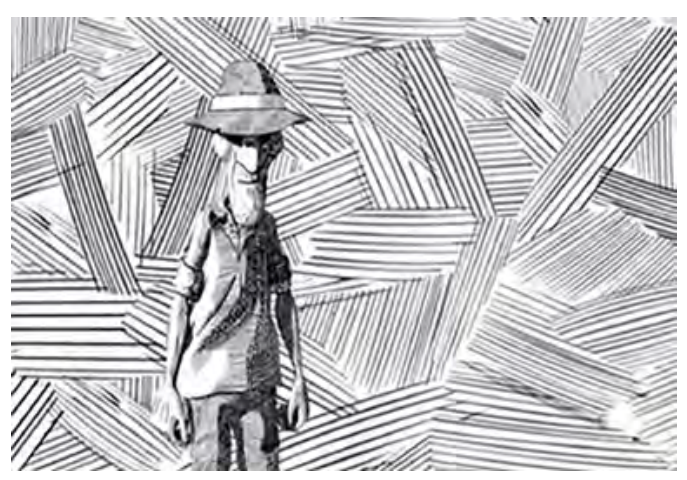

Fonte: disponível em: <http://tvescola.mec.gov.br/tve/ home>.

O recorte reforça a ideia do retirante, de costas para a sua terra, em deslocamento espacial, em busca da transformação de um estado de secura à humidade, da esterilidade à fertilidade, da frieza ao aquecimento, do desespero à esperança. Embora sua situação homem osso esteja, na figura, em primeiro plano, parece se fundir com a própria natureza da terra árida, bruta, em segundo plano, como se o primeiro fosse o reflexo do segundo.

Mas o Severino não desiste. Ele ainda está de pé. A verticalidade da vida opõe-se à horizontalidade da morte, representada pelos tracemas, linhas que se cruzam, que se entrelaçam como uma rede em que se descansa, em que jaz um corpo sem vida. Esses mesmos tracemas formam também grande parte dos espa- 
ços retratados, como o chão, o céu e as plantas, transmitindo toda a aridez já revelada pelos imensos espaços vazios que aparecem como pano de fundo da animação.

A linguagem verbal do poema encontra aqui o suporte não verbal, quando o desenho apresenta a entrada da figura dos cactos a indicar o caráter discursivo que se adianta e que recobre o texto todo, tornando clara a isotopia viso-temática da retilineidade (tracemas retilíneos englobantes), para a retratação do caráter verbo-sincrético, conforme apresentado na Figura 6.

Figura 6 - Morte e vida Severina - desenho animado

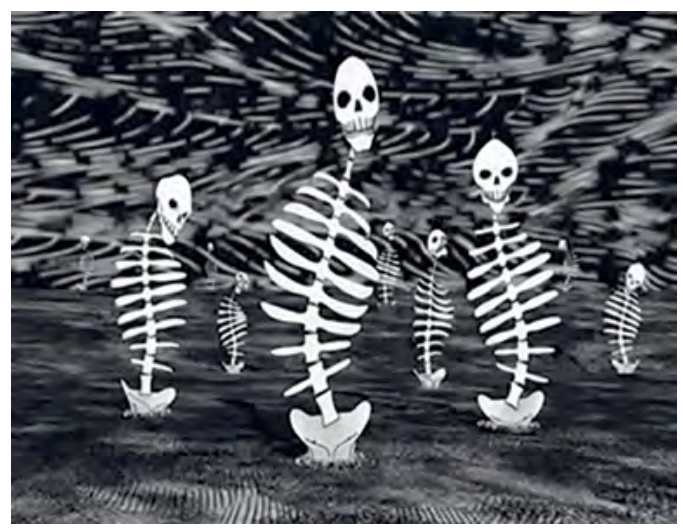

Fonte: disponível em: <http://tvescola.mec.gov.br/tve/ homes.

A animação Morte e vida Severina já carrega em seu título a oposição vida versus morte, o que incide diretamente na escolha dos coloremas branco versus preto, que são as cores predominantes no desenho e que, comumente, são associadas à morte e à vida na cultura ocidental.
Segundo D’Ávila (2015, p. 108), tracemas são os semas do traço/linha, i.e. os traços ou linhas que unem os pontos (pontuemas):

A linha, enquanto iteratividade dos pontos/ traços, é uma unidade de base mínima primitiva e significativa na imagem. Ela é, enquanto signo, a menor distância entre dois pontos/traços. Essa linha tem superfície, posicionamento, direcionalidade e finitude, definida por seus tracemas [...] (D'ÁVILA, 2015, p. 108).

Os tracemas curvilíneos são menos frequentes na animação, estão presentes principalmente nas personagens que vivem na parte menos árida, na qual Severino termina a sua trajetória. Se os tracemas retilíneos são utilizados para expor a miséria e a fome, os curvilíneos agem no sentido oposto, demonstrando a vivacidade, a juventude, a dinâmica da vida, como no exemplo da criança que nasce no fim do poema.

A isotopia da horizontalidade é fundamental para a animação. Velórios, covas e assuntos fúnebres são temas que convergem para a temática da morte em oposição à vida. A divisão entre o céu limpo e branco, representando o sol forte, e o chão rachado, com uma quantidade ínfima de plantas, tem a representação da mesma categoria semântica da vida em oposição à morte. $\mathrm{O}$ poema enfatiza a terra e o céu como extremos.

$O$ recorte da animação da figura 6 mostra o homem osso que se desfaz e se transforma em homem caveira, em uma representação da morte em oposição à vida em cujos ossos havia se revestido. É 
assim que chegamos ao figural em oposição ao figurativo, aquele traço inicial de onde surgiu a ideia de homem, na pressuposição da existência, de ter havido a vida, já pertencente ao nível figurativo, na impressão de que é pela morte, pelo esvaziamento, pelo desrevestimento que se chega à essência do ser, daquele traço inicial de onde surgiu, da rachadura da terra, da rachadura dos pés, da fusão do natural com o cultural. Ao final, o humano, produto de uma cultura, o fenômeno que se mostra no nível do parecer como homem se transforma, em uma isotopia fusional, no figural, no numenal, como produto da própria natureza.

Embora homens-caveiras, representação da morte, os tracemas curvilíneos fazem a diferença, porque são eles os responsáveis pela quinese, pelo movimento, pela dinamicidade em oposição à estaticidade do poema, formada pelos traços retilíneos. São esses os primitivos figurais que vão se transformar nos figurativos, os primeiros da ordem da expressão e os segundos do plano do conteúdo.

A isotopia da verticalidade em oposição à horizontalidade é notória no recorte que fazemos da animação que passa a forma estática na primeira figura, quando $o$ homem caveira nos faz lembrar do touro linha de Picasso. É a tentativa do analista e do produtor da animação, do poeta, enfim, de todos aqueles que se preocupam com o sentido da vida de encontrar a sua essência, o traço inicial, tracema no dizer de D’Ávila, ou o pontuema, o ponto inicial que gerou aquele específico ser, que, no nível do parecer, está mais para a morte do que para a vida.

\section{Conclusão}

As reflexões aqui postas devem continuar. Elas representam apenas um fazer pragmático e cognitivo que encaramos em sua parcialidade, porque a essência das coisas continua sendo objeto de busca, limitando-nos aos efeitos de sentido, verificando a transposição do poema para o desenho animado, da teoria de Greimas para a proposta de D'Ávila, que oferece um caminho metodológico para se aplicar a teoria do mestre lituano, com inovações, ao texto sincrético.

Em relação à obra de Miguel Falcão, essa contribui, sim, para a realização de um querer posto por João Cabral de Melo Neto, ao sugerir que todos os meios deveriam ser usados pelos poetas a fim de promover a afetividade da linguagem por meio da poesia, estendendo seu raio de alcance com produções intersemióticas como aquela aqui referenciada.

Quanto à teoria da figuratividade visual, podemos dizer que se firma como instrumento importante para a verificação do sentido formado pelos pontos, traços, linhas que se portam no nível figural e que se transformam em pontuemas, tracemas e formadores de sentido no nível figurativo, no que se refere à linguagem não verbal, os primeiros como participantes do plano da expressão e os segundos do plano do conteúdo. D’Ávila, com sua 
teoria, com base em Greimas, contribui com a análise de objetos que incluem a linguagem não verbal e sincrética, como o desenho animado Morte e vida Severina, que popularizou, sem dúvida, a obra de João Cabral de Melo Neto.

\section{Intersemiotics and semiotics of visual figurativeness in Morte e vida Severina, by João Cabral de Melo Neto}

\begin{abstract}
Starting from the concepts of intersemiotics, this article deals with the passage from the poem to the comics, from comics to animation, to kinesics, sailing through the concepts of the work of art to Walter Benjamin, from the translation to Roman Jakobson, from the aesthetic sign, from the transposition from one to Another language in Morte e vida Severina by João Cabral de Melo Neto based on Julio Plaza and his work Tradução intersemiótica. In a second moment, it presents considerations on dialogues between Peirce and Greimas in the wake of Nícia Ribas D'Ávila, culminating in an analysis, under the effects of meaning, of the homonymous cartoon, an audiovisual version of the Pernambuco poet, adapted for comic strips by the cartoonist Miguel Falcão by means of the visual figurative theory of Greimasian inspiration, at which point the semantic category of stillness versus dynamicity is identified as the main pair between the language used in the poem and that of the cartoon.
\end{abstract}

Keywords: Intersemiotic. Aesthetic sign. Semiotics of figurativeness.

\section{Notas}

1 Disponível em: <https://disciplinas.stoa.usp.br/ pluginfile.php/321070/mod_resource/content/1/ JAKOBSON\%20tradu\%C3\%A7\%C3\%A3o,\%20 lingu \% C 3\% ADstica, \% 20 un \% C 3\% A $7 \%$ C3\%A3o\%20po\%C3\%A9tica.pdf>. Acesso em: 29 nov. 2016.

2 Approche semiotique du fait musical bresilien "batucada" par Nícia Ribas D’Ávila. davila. Disponível em: com.br/wordpress/?page_id=2506. Acesso em: 28 nov. 2016.

3 Tradução nossa para a definição do "The Free Dictionary by FARLEX" "A device or theoretical construct with known or specified performance characteristics but unknown or unspecified constituents and means of operation". Disponível em: <http://www.thefreedictionary. com/ black+box>. Acesso em: 28 nov. 2016.

4 Os livros organizados por D'Ávila são: Semiótica sincrética aplicada: novas tendências (2007) e Semiótica verbal e sincrética verbo-visual e verbo-musical, teorias e aplicabilidade (2015). Para uma ideia do volume de sua publicação, acessar: <http://www.niciadavila.com.br/>.

5 Anais do SIELP. Disponível em: <http://www. ileel.ufu.br/anaisdosielp/wp-content/uploads/2014/11/78.pdf>. Acesso em: 28 nov. 2016.

6 Disponível em: <http://www.releituras.com/ joaocabral_bio1.asp $>$. Acesso em: 10 maioLink I. 2015. Disponível em: <http://tvescola.mec. gov.br/tve>. Acesso em: 29 nov. 2016. Link II.

\section{Referências}

BIRDWHISTELL, Ray L. A análise quinésica. In: GREIMAS, A. J. Prática e linguagens gestuais. Lisboa: [s.n.], 1979. p. 143-158.

BENJAMIN, Walter. A obra de arte na era da sua reprodutibilidade técnica. In: A ideia de cinema. GRUNNEWALD, José Li no . Rio de Janeiro: [s.n.], 1961. p. 55-95,

D’ÁVILA, Nícia Ribas. Approche semiotique du fait musical bresilien "batucada". Thèse de doctorat en Sémiologie Sous la direction de Algirdas Julien Greimas. Soutenue en 1987 à Paris 3. 
. Comunicação visual: simbolismo e semi-simbolismo na teoria semiótica da figuratividade visual. In: (Org.). Semiótica sincrética aplicada: novas tendências. São Paulo: Arte e Ciência, 2007. p. 15-52.

. Diálogos entre C. S. Peirce e A.-J. Greimas. In: AGUILERA, V. A.; LÍMOLI, L. (Org.). Entrelinhas, entretelas: os desafios da leitura. Londrina: Editora UEL, 2001. p. 65-78.

Semiótica verbal e sincrética, verbo-visual e verbo-musical teorias e aplicabilidade. Bauru, SP: Canal 6, 2015.

GREIMAS, A. J. Prática e linguagens gestuais. Lisboa: [s.n.], 1979.

JAKOBSON, Roman. Os aspectos linguísticos da tradução. 20. ed. In: JAKOBSON, Linguística e comunicação. São Paulo: Cultrix, 1995.

KRISTEVA, J. O gesto, prática ou comunicação? In: GREIMAS, A. J. Prática e linguagens gestuais. Lisboa: [s.n.], 1979. p. 77-95.

MELO NETO, João Cabral de. Melhores poemas João Cabral de Melo Neto. 10. ed. São Paulo: Global, 2010. (Antonio Carlos Secchin, seleção e prefácio - Edla Van Steen, direção).

. Obra completa. 2. ed. Rio de Janeiro: Nova Aguilar, 2008.

PEIRCE, Charles Sanders. Collected Papers of Charles Sanders Peirce. Ed. by C. Hartshorne \& Paul Weiss (v. 1-6) A. Burks (v. 7-8). Cambridge, MA: Harvard University Press, 1931-1958. 8 v. (Referido no texto como CP 2.249, tradução nossa do original). Disponível em: <http://www.zbi.ee/ kalevi/ Peirce2.htm>. Acesso em: fev. 2017.

PLAZA, Júlio. Tradução intersemiótica. São Paulo: Perspectiva, 2003.

SANTOS, Valdenildo dos. A música e seus efeitos de sentido como motivadores no ensino de línguas. Diálogos Pertinentes, Franca, São Paulo, v. 10, n. 1, p. 113-128, 2014. 